\title{
The Near Abasement of Uganda Hotels' Staff Altruistic Behaviour by COVID-19 Pandemic: A Relief Model
}

\author{
By Joshua Gukiina* \& Elizabeth Lamunu ${ }^{ \pm}$
}

\begin{abstract}
This paper aims to analyze the relationship between employee optimism, status competitiveness, interpersonal adaptability and employee altruism during the COVID-19 pandemic. In addition, it examined the mediating effect of interpersonal adaptability and employee optimism in the stated relationship. A quantitative study was conducted using a sample of 303 respondents that constituted both managers and employees from 70 selected hotels in Uganda shortly after the end of the first lockdown in July, 2020. The associated hypotheses were tested using the Smart-PLS 3.2 software. Once employees are optimistic, undergo free and fair competition for any position, and feel that they freely interact with one another, then they are bound to devote themselves to the welfare of one another at all costs. It examined employee optimism, status competitiveness, and interpersonal adaptability as explanations of employee altruism. This is in addition to the mediation effect of interpersonal adaptability and employee optimism in the stated relationship. In terms of its value, when employees have positive expectations regardless of the current challenges they undergo, there is fair competition for all positions in the organization, and that they interact freely, they can offer help for others' welfare.
\end{abstract}

Keywords: employee optimism, status competitiveness, interpersonal adaptability, employee altruism, organizational citizenship behavior and COVID-19

\section{Introduction}

The devotion to the welfare of others underlies the summative essence of employee altruistic behaviour. This is because it precisely denotes an act of sacrificing or risking one's own interests for the sake of another(s), usually at less or no personal cost (Savulescu and Wilkinson 2020). It involves those fairly small but timely and relevant sacrifices to the recipient, such as: attending to a sick colleague in a hospital, donating a kidney to a family member and standing in for a coworker just because he or she is unable. Altruism was derived from a Latin word "alter" which means "other," and its first application is merrily associated with Auguste Comte in the 1830s (Green 2005) who used it to mean caring for others.

However, while the largest percentage of altruism involves little or no cost, this behaviour has in certain cases been offered in extreme circumstances. For instance, some people offer to work for the helpless away from their home countries. To date, we continue to witness cases where medics have walked the extra mile to provide medical care to the sick. In times of war and violence, the services of the Red Cross are by no means merely an illustration. While this

\footnotetext{
*Lecturer, Makerere University Business School, Jinja Campus, Uganda.

${ }^{ \pm}$Lecturer, Makerere University Business School, Jinja Campus, Uganda.
} 
behavior continues to be demonstrated by people in our respective societies, in Uganda, the hotel industry has been hit big by the COVID-19 pandemic. Following the ease in lockdown measures, the response mechanisms in place have, and continue to threaten, altruistic employee behaviours. For instance, through the help of personal observation, there is glaring disregard for personal assistance. Workmates no longer easily step in to offer assistance to a friend in-need; this is regardless of such ongoing measures such as sanitization, wearing masks, let alone social-distancing. There are marked diminishing employee feelings of concern and empathy for others let alone their hitherto actions that benefit one another. This has stretched to even affect clients. What is important to note is that the dictates of altruism warrant that, even in such extreme situations, employees are still expected to act in such ways that continue to benefit others even when there is evident fear of personal risks (Savulescu and Wilkinson 2020).

Based on these observations, some of the explanations for the reduction in employee altruistic behaviors that were provided by the selected staff we interacted with, were but not limited to a reduction in employee optimism, interpersonal adaptability and status competitiveness. According to those interviewed, they observed that generally staff continue to believe that COVID-19 is real and here to stay. Therefore, they do not envisage proper mechanisms through which to secure their lives (not optimistic). What worries most is that some staff were laid-off since very few clients visit to hotels to date. Therefore, they better relax the extent of care that they have been offering to both their colleagues and clients. For as long as they can be retained on their jobs, so be it. In addition, due to social distancing as a COVID-19 response mechanism, there is no opportunity to freely interact with one another, either with clients or colleagues. This is the essence of absence of interpersonal adaptability. Actually, employees are now being challenged to accept this as a new normal until further notice, since to date, it is hard to tell who is with the infection given that many people are asymptomatic. Therefore, the need to easily socialize and relate with others so as to enhance productive behaviors within the hotels has so far hit a snag. In addition, as for status competitiveness, due to status differences, supervisors are now too bossy, therefore, isolated from their subordinates, reserved, often stay on their desks, irregularly move around and about the hotels and do not wish to easily mix with subordinates. The consequence of all these abating factors is that the selfless behaviors (altruistic behaviors) that inevitably foster individual and organizational efficiency and effectiveness, have significantly declined.

\section{Theoretical Background}

In order to attach a theoretical lens to the relationship between employee optimism, status competitiveness, interpersonal adaptability and employee altruism in the context of Uganda hotels, two theories have been adapted. These are: the Interpersonal Theory (Kiesler 1996) and the Social Comparison Theory (Festinger 1954). 


\section{Employee Optimism, Status Competitiveness Interpersonal Adaptability and Employee Altruism}

In this study, employee altruism refers to the assistance or care that employees offer to their colleagues at little or no cost without expecting to be rewarded (Savulescu and Wilkinson 2020). Employee optimism is taken to mean the generalized feeling amongst people that positive experiences will occur in the future while those that are negative will be minimized (Carver and Scheier 2014). Status competitiveness refers to the struggles that are associated with the socially accepted ranking of individuals, groups, or activities in any social structure (Washington and Zajac 2005). Interpersonal adaptability refers to the flexibility and willingness to interact with others in different situations (Kiesler 1996).

\section{The Interpersonal Theory (Kiesler 1996)}

This theory is derived from the notion of interpersonal reciprocation. This view argues that people in a relationship choose to behave in such ways that maintain or reflect similar previous actions and expectations towards each other. This implies that the actions of one party in a relationship simply depict and reaffirm what the other did before. The result is a relationship characterized by a give and return behavior amongst the interactants. To this extent, it could be argued that people in an interaction are usually flexible to the extent that they reciprocate what each other does (interpersonal adaptability). This is to the extent that whenever one party behaves in a particular way, he or she remains expectant that at some point in time, the other party will behave in a similar manner. This is the essence of employee optimism. Further, it is should be overtly stated that in an effective interpersonal interaction, since positive expectations (optimism) are characteristic, offering help to one another (altruism) in such a relationship at little or no cost without expecting to be rewarded could result. This is as such to indicate that the interpersonal theory can explain employee optimism, interpersonal adaptability and employee altruistic behaviors. However, while there is a basis for an inference that employee optimism, interpersonal adaptability and employee altruism could be related, this is not to imply that the theory advances the argument that interpersonal adaptability, mediates in the relationship between employee optimism and employee altruism. Further, the theory does not in any way reflect the argument that interpersonal behaviors are competitive at all. This is because each action of a party in an interaction is voluntarily induced by the actions of the other (Kiesler 1996). Indeed, this is the basis of the integration of the social comparison theory (Festinger 1954), which advances the element of competition in a social system so as to rise or maintain a particular social status in an organization.

Empirically, while there is scanty literature to attest to a relationship between employee optimism, status competitiveness interpersonal adaptability and employee altruism, somehow, the works of Xiao et al. (2020) fragmentally suggest so. This is because, they argue that workplace friendship is the manifestation of interpersonal relationships in the workplace. It is important to note that workplace friendship not only manifests interpersonal relationships, but as well, employee optimism, interpersonal adaptability and selfless helping behavior (altruistic 
behavior). However, this possible relationship is devoid of traits of status competitiveness. Besides, while Xiao et al. (2020) make a possible basis against which to infer the stated relationship, they do not attempt in any way to state that, interpersonal adaptability and employee optimism, are possible mediators of the relationship under investigation.

Further, the works of Yin et al. (2018) could equally be a basis for inferring that a possible relationship between employee optimism, status competitiveness interpersonal adaptability and employee altruism, could be existent. To these scholars, workplace friendship can positively affect employees' attitudes toward work, and as such, their mates. It could be humbly argued that workplace friendship cannot exist without such employee perceptions of optimism, interpersonal adaptability and selfless behaviors towards one another. This is because their absence implies lack of friendship at the workplace. In this respect, the fact that they move hand-in-hand they could as well be related. However, just as it has been the case in the foregoing scholarly works, Yin et al. (2018) does not as well propose that interpersonal adaptability and employee optimism mediate in the assumed relationship. Besides, these scholars remain silent about a possible inherent inclusion in the hypothesized relationship, status competitiveness.

Equally, Wei et al. (2019) could allude to a possible relationship between employee optimism, status competitiveness interpersonal adaptability and employee altruism. This is because, to these scholars, a negative emotional state in employees has a direct effect on their work attitude and thoughts and this affects their extra role behaviors. By implication, when employees have positive emotions such as when they are optimistic, they are bound to have positive work attitudes such as easily integrating with each other which subsequently leads to extra role behaviors such as altruism. These scholars however do not propose that subsequently, in such a relationship, status competitiveness is inherent, and that the said relationship could be mediated by interpersonal adaptability and employee optimism. Therefore, to this extent, it was possible to hypothesize that:

$\mathrm{H}_{1}$. Employee optimism is significantly related to employee altruism.

$\mathrm{H}_{2}$. Employee optimism is significantly related to interpersonal adaptability.

$\mathrm{H}_{3}$. Interpersonal adaptability and employee altruism are significantly related.

$\mathrm{H}_{4}$. Interpersonal adaptability mediates in the relationship between employee optimism and employee altruism.

\section{Employee Optimism, Status Competitiveness Interpersonal Adaptability and Employee Altruism}

\section{The Social Comparison Theory (Festinger 1954)}

This theory posits that individuals in a social system choose to perform better than others. In return, the urge to always do better than others introduces competitive behavior amongst them. Therefore, given that competition is driven by associated privileges, such as a rise in rank or social status, competition is part of human behavior in any social system. In relation to the current study, status competitiveness is inherent in the Uganda hotels' management structures. This is 
because, due to competition, superiority in performance amongst workers has accrued, and in return, some occupy lower ranks than others. It is those in superior positions that have chosen to remain reserved, keep busy around their desks and do not move around and about the hotels to supervise others due to the fear of COVID-19. This has led to the continuing inflexibility amongst the workers to the extent that employees practically do not blend with one another easily even when it comes to offering each other the necessary assistance (altruistic behaviors) intended to enhance their hotels' efficiency and effectiveness. This is why there is a marked reduction in employee altruism yet these behaviors are critical to the hotels' productivity, although employees are always optimistic whenever they compete through performance enhancement. However, regardless of this implied relationship amongst status competitiveness, employee optimism, interpersonal adaptability and employee altruistic behaviors, to date, there is a paucity of scholarship that attempts to link these constructs. Besides, there is a lack of scholarly evidence to suggest that interpersonal adaptability mediates in the relationship between status competitiveness and employee altruistic behaviour.

In addition, a quick review of the scanty empirical literature relating employee optimism, status competitiveness, interpersonal adaptability and employee altruism, indicates that there could exist a basis against which to hesitantly argue for a derived relationship amongst these variables, however, one that is marked with significant weaknesses that justified the need for this investigation.

For instance, to Anjum et al. (2019), when there is a high level of friendship amongst workers in an organization, the near equivalent of interpersonal adaptability, employees respond by demonstrating strong willingness to share what they have with colleagues, resurrection of emotional needs such as optimism, the will to continue working in the organization in any capacity of choice, the equation to status competitiveness and obviously wanting to help each other at all costs (altruism). Under such an environment, it is possible to argue that these variables are related, considering that all could exist under the same conditions. However, while it is possible to assume this relationship, it is important to note that the relationship is just a derivative of a study that had an entirely different set of variables. Besides, these scholars do not permit a sense of a conclusion that interpersonal adaptability and employee optimism could mediate in a relationship that is being assumed. In addition, the theoretical lens that Anjum et al. (2019) employed to anchor this study is contrary to what the current study has adapted. This implies a contradiction in the constructs' validity of the respective studies.

In a related argument by $\mathrm{Yu}$ et al. (2021), there is another point of view against which to derive a possible linkage amongst these variables, but definitely with marked weaknesses. These scholars argue that workplace friendship results in the achievement of individuals' emotional needs in the organization, knowledge sharing, mutual help among workmates, harmonious working atmosphere characterized by mutual trust and love and increased resource investment in extrarole behavior. In the preceding argument, work friendship was treated as the equivalent of interpersonal adaptability which has the potential to lead to emotional needs such as employee optimism, mutual help among workmates (employee altruism). It could reluctantly be argued that against such a background, the spirit 
of competition for the different positions in the organizational structure could be present. However, until now, even when this relationship could be assumed, it is ideally a derived one without any sufficient empiricism. Besides, the mediation tests alluded to in the present study, are not mentioned anywhere in the study by Yu et al. (2021). Therefore, it was necessary then to hypothesize that:

$\mathrm{H}_{5}$. Status competitiveness is significantly related to interpersonal adaptability

$\mathrm{H}_{6}$. Status competitiveness and employee altruism are significantly related.

$\mathrm{H}_{7}$. Interpersonal adaptability mediates in the relationship between status competitiveness and employee altruism.

$\mathrm{H}_{8}$. Employee optimism mediates in the relationship between status competitiveness and interpersonal adaptability.

$\mathrm{H}_{9}$. Employee optimism is mediates in the relationship between status competiveness, and employee altruism.

\section{Methodology}

\section{Study Population, Sample Size and Procedure}

The staffing of hotels in Uganda was investigated. There are 516 hotels in Uganda (www.jovago.com/ Uganda hotels). For the purpose of this study, out of the stated total number of hotels (516), 220 hotels were selected randomly from the list of hotels using a simple random sampling technique. After contacting each one of those that had been selected, 100 hotels accepted to participate in the study. 5 questionnaires were then distributed to 5 people in each of the 100 hotels that appeared in the final sample for this study. Of the five (5) potential respondents, one (1) was a supervisor and four (4) were subordinates. This selection approach led to the distribution of 500 questionnaires to 500 potential respondents. Out of the 500 questionnaires distributed, 350 were realized. This means that 150 questionnaires were never realized. This implies that an average of seventy (70) hotels finally participated. Therefore, the final usable sample was three hundred fifty (350) respondents which dropped to (303) after data-cleaning. These hotels were located in 16 districts of Uganda but they had not been classified because, until now, the hotel classification in Uganda is still ongoing.

\section{Operationalization and Measurement of Study Variables}

The study variables were operationalized based on earlier scholarly works. Four variables were examined which are: employee optimism, status competitiveness, interpersonal adaptability and employee altruism. All the items that measured these variables were anchored on a five point likert scale which ranged from $1=$ strongly disagree to $5=$ strongly agree. This is because this scale provides a neutral middle point which caters for a condition in which a respondent may not have an opinion on the question at hand (Chung Ho Yu 2008). The description of the measurements for each variable is as follows: 


\section{Employee Optimism}

The unidimensional scale by Cameron et al. (2004) was modified for this study. It consists of six items that directly measure employee optimism. Some of the sample items include: "As employees of this organization, we are optimistic that we will succeed, even when faced with major challenges." This was modified to read as follows: "As employees of this hotel, even under this COVID-19 pandemic situation, we are optimistic that we will succeed, even when faced with major challenges." The second item is: "In this organization, we are dedicated to doing good in addition to doing well." This was modified to read as follows: "In this hotel, regardless of the COVID-19 pandemic situation, we are dedicated to doing good in addition to doing well."

\section{Status Competitiveness}

The one-dimensional scale of status competitiveness by Fletcher and Nusbaum (2010) was modified for this study. It is constituted by seventeen items that measure status competitiveness. Some of the sample items include: "My status at work depends on my performance relative to others." This was modified to read as follows: "Under this COVID-19 pandemic situation, my status at work depends on my performance relative to others." The second item: "My achievements are routinely compared to those of my coworkers." This was modified to read as follows: "Under this COVID-19 pandemic situation, my achievements are routinely compared to those of my coworkers."

\section{Interpersonal Adaptability}

This was measured using the unidimensional scale of Charbonnier-Voirin and Roussel (2012). This scale consists of five items that measure interpersonal adaptability. Some of the sample items include: "I adapt my work practices to the requirements and suggestions of others." This was modified to read as "under this COVID-19 pandemic situation, I adapt my work practices to the requirements and suggestions of others." The second item: "I try to understand the viewpoints of my counterparts to improve my interaction with them." "Under this COVID-19 pandemic situation, I try to understand the viewpoints of my counterparts so as to improve my interaction with them."

\section{Employee Altruism}

The one-dimensional scale by Organ (1988) was adapted for this study. It is a six-item scale that measures employee altruistic behaviors. Some of the sample items include: "Helps others who have heavy workloads in this organization." This was modified to read as follows: "Regardless of this COVID-19 pandemic situation, I help others who have heavy workloads in this hotel." The second item: "Helps others who have been absent in this organization." This was modified to read as follows: "Regardless of this COVID-19 pandemic situation, I help others who have been absent in this hotel." 


\section{Common Method Bias}

To control for common methods bias, we kept questions short and precise, avoided double-barreled questions and limited the use of negatively worded items. We ensured respondents' anonymity which enabled them to give unbiased responses. Further, we conducted multiple follow-up calls and email reminders for those who delayed to answer the questionnaire. In addition, we adapted previously validated measurement scales to suit the study context. We also contacted three professional academics and two managers to ensure the items were clear and captured their respective constructs. We further used four respondents for each sampled unit of analysis, whereby we received 303 questionnaires in 70 hotels.

\section{Measurement Validation}

We assessed the convergent validity of the item using two criteria; standardized item load of above 0.708 and average variance extracted (AVE) above 0.5 . The results in Table 4 indicate that these two criteria were met as recommended by Hair et al. (2017), indicating that the items measure what they are intended to measure. Internal consistence was assessed in terms of Cronbach's Alpha and composite reliability by considering indices above 0.6 (Hair et al. 2017). The results reveal that the coefficient for the study variables - altruism, interpersonal adaptability, optimism and status competitiveness-are all well above the 0.6 threshold, indicating that the data is reliable.

Table 1. Measurement Validation Results

\begin{tabular}{|l|c|c|c|c|c|c|c|c|}
\hline $\begin{array}{l}\text { Measures / } \\
\text { Constructs }\end{array}$ & $\begin{array}{c}\text { Weight/ } \\
\text { Loadin } \\
\mathbf{g}\end{array}$ & $\mathbf{V I F}$ & $\begin{array}{c}\mathbf{C V}^{2} \\
\text { Communality }\end{array}$ & $\begin{array}{c}\mathbf{C V}^{2} \\
\text { Redundanc } \\
\mathbf{y}\end{array}$ & $\boldsymbol{\alpha}$ & $\begin{array}{c}\text { Rho- } \\
\mathbf{A}\end{array}$ & $\mathbf{C R}$ & $\begin{array}{c}\text { AVE } \\
\mathbf{1}\end{array}$ \\
\hline ALT1 & 0.768 & 1.137 & 0.33 & & & & & \\
\hline ALT6 & 0.754 & 1.418 & 0.43 & & & & & \\
\hline ALT7 & 0.746 & 1.365 & 0.32 & & & & & \\
\hline Altruism & & 1.730 & 0.34 & & 0.634 & 0.638 & 0.800 & 0.571 \\
\hline IA1 & 0.912 & 2.992 & 0.34 & 0.28 & & & & \\
\hline IA3 & 0.810 & 1.793 & 0.35 & 0.30 & & & & \\
\hline IA5 & 0.790 & 1.855 & 0.26 & 0.27 & & & & \\
\hline IA9 & 0.807 & 1.926 & 0.31 & 0.28 & & & & \\
\hline $\begin{array}{l}\text { Interpersonal } \\
\text { Adaptability }\end{array}$ & & 1.436 & 0.29 & 0.23 & 0.850 & 0.861 & 0.899 & 0.691 \\
\hline OPT1 & 0.847 & 1.312 & 0.49 & 0.34 & & & & \\
\hline OPT4 & 0.663 & 1.166 & 0.47 & 0.35 & & & & \\
\hline OPT5 & 0.743 & 1.276 & 0.38 & 0.29 & & & & \\
\hline Optimism & & 1.706 & 0.46 & 0.35 & 0.625 & 0.666 & 0.797 & 0.570 \\
\hline SCOMP2 & 0.728 & 1.267 & 0.37 & 0.35 & & & & \\
\hline SCOMP3 & 0.831 & 1.361 & 0.36 & 0.34 & & & & \\
\hline SCOMP4 & 0.735 & 1.224 & 0.37 & 0.35 & & & & \\
\hline $\begin{array}{l}\text { Status } \\
\text { Competitiveness }\end{array}$ & & 1.740 & 0.45 & 0.41 & 0.649 & 0.664 & 0.810 & 0.587 \\
\hline
\end{tabular}




\section{Discriminant Validity}

In order to show the distinction between items (or a set of items) for the study constructs, discriminant validity tests were performed (Henseler et al. 2015). Based on the results in Table 1 it can be stated that there was discriminant validity at the item level due to the high correlation between items of the same construct, and a very weak correlation between items of the different constructs (Henseler et al. 2015).

In addition, as a new method for assessing discriminant validity in partial least squares structural equation modeling, Heterotrait-Monotrait ratio of correlations (HTMT) was applied (Henseler et al. 2015). According to these scholars, if the HTMT value is below 0.85 , discriminant validity has been established between two reflective constructs. In this regard, based on the results in Table 2, the HTMT value was below 0.85 and as such, there was discriminant validity. The results are shown in Table 3.

Table 2. Fornell-Larcker Criterion Results

\begin{tabular}{|l|c|c|c|c|}
\hline & Altruism & $\begin{array}{c}\text { Interpersonal } \\
\text { adaptability }\end{array}$ & $\begin{array}{c}\text { Optimis } \\
\text { m }\end{array}$ & $\begin{array}{c}\text { Status } \\
\text { competitiveness }\end{array}$ \\
\hline Altruism & 0.756 & & & \\
\hline $\begin{array}{l}\text { Interpersonal } \\
\text { adaptability }\end{array}$ & 0.533 & 0.831 & & \\
\hline Optimism & 0.472 & 0.539 & 0.755 & \\
\hline Status competitiveness & 0.474 & 0.605 & 0.635 & 0.766 \\
\hline
\end{tabular}

Table 3. Heterotrait-Monotrait Ratio (HTMT) Results

\begin{tabular}{|l|c|c|c|c|}
\hline & Altruism & $\begin{array}{c}\text { Interpersonal } \\
\text { adaptability }\end{array}$ & Optimism & $\begin{array}{c}\text { Status } \\
\text { competitiveness }\end{array}$ \\
\hline Altruism & & & & \\
\hline $\begin{array}{l}\text { Interpersonal } \\
\text { adaptability }\end{array}$ & 0.701 & & & \\
\hline Optimism & 0.704 & 0.712 & & \\
\hline Status competitiveness & 0.712 & 0.807 & 0.767 & \\
\hline
\end{tabular}

Further, according to Gefen and Straub (2005), discriminant validity is shown when each measurement item correlates weakly with another construct except for the ones to which it is theoretically associated. Based on results of the cross loadings below, it can be stated that there was discriminant validity amongst the study constructs since each measurement item correlated weakly with another construct except for the ones to which it is theoretically associated. The results in Table 4 indicate discriminant validity based on the cross loadings. 
Table 4. Cross Loadings

\begin{tabular}{|l|c|c|c|c|}
\hline & Altruism & Interpersonal adaptability & Optimism & Status competitiveness \\
\hline ALT1 & 0.768 & 0.470 & 0.447 & 0.416 \\
\hline ALT6 & 0.754 & 0.311 & 0.336 & 0.275 \\
\hline ALT7 & 0.746 & 0.400 & 0.260 & 0.359 \\
\hline IA1 & 0.502 & 0.912 & 0.522 & 0.553 \\
\hline IA3 & 0.470 & 0.810 & 0.414 & 0.510 \\
\hline IA5 & 0.376 & 0.790 & 0.330 & 0.455 \\
\hline IA9 & 0.411 & 0.807 & 0.505 & 0.487 \\
\hline OPT1 & 0.447 & 0.509 & 0.847 & 0.588 \\
\hline OPT4 & 0.270 & 0.320 & 0.763 & 0.405 \\
\hline OPT5 & 0.323 & 0.360 & 0.743 & 0.417 \\
\hline SCOMP2 & 0.283 & 0.415 & 0.443 & 0.728 \\
\hline SCOMP3 & 0.400 & 0.531 & 0.569 & 0.831 \\
\hline SCOMP4 & 0.397 & 0.435 & 0.435 & 0.735 \\
\hline
\end{tabular}

\section{Results}

\section{Descriptive Statistics}

We relay the descriptive statistics the characteristics of the respondents, and hotels that were surveyed. This is as follows:

\section{Characteristics of the Respondents and Response Rate}

The average age range of the respondents was 20-25 years. Results revealed that $67 \%$ of the respondents were male and $33 \%$ were female. In total, the final sample constituted three hundred and three respondents (303).

The survey attained a $90 \%$ response rate from the units of inquiry that were Uganda Hotel staff. This was only possible because the investigator requested respondents to spare some time to fill the questionnaires and indeed made many follow-up trips to the selected hotels. Otherwise, the hotel staff were ever busy that it became very hard to secure $100 \%$ response rate.

\section{Characteristics of the Hotels Surveyed}

The number of hotels that finally constituted the sample was seventy (70). Their characteristics are reported in terms of: number of years that the hotel had been in existence, the number of rooms that the hotel possessed, the number of employees that the hotel had employed at the time of the investigation and its form of ownership. This was in terms of whether it was government or private. Table 5 breaks them down as follows. 
Table 5. Characteristics of the Hotels Surveyed

\begin{tabular}{|c|c|c|c|c|}
\hline No. & Item & Ranges & Sub total & Total \\
\hline \multirow{5}{*}{1} & \multirow{5}{*}{$\begin{array}{l}\text { No. of years in } \\
\text { existence }\end{array}$} & Less than 10 & 27 & \multirow[b]{5}{*}{70} \\
\hline & & Between 11-20 & 20 & \\
\hline & & Between 21-30 & 23 & \\
\hline & & Above 31 & 10 & \\
\hline & & Total & & \\
\hline \multirow{5}{*}{2} & \multirow{5}{*}{ No. of rooms } & Less than 40 & 20 & \multirow[b]{5}{*}{70} \\
\hline & & Between 50-100 & 25 & \\
\hline & & Between 101-150 & 15 & \\
\hline & & Above 150 & 10 & \\
\hline & & Total & & \\
\hline \multirow{5}{*}{3} & \multirow{5}{*}{ No. of employees } & Less than 20 & 20 & \multirow[b]{5}{*}{70} \\
\hline & & Between 21-40 & 10 & \\
\hline & & Between 11-60 & 35 & \\
\hline & & Above 60 & 5 & \\
\hline & & Total & & \\
\hline \multirow{3}{*}{4} & \multirow{3}{*}{ Ownership } & Government & 0 & \multirow[b]{3}{*}{70} \\
\hline & & Private & 70 & \\
\hline & & Total & & \\
\hline
\end{tabular}

Source: researcher's computation.

\section{Correlation Analysis Results}

Table 5 presents the means, standard deviations and zero order correlations amongst the study constructs. This is because means depict a summary of the data, whereas standard deviations indicate how well the means represent the data (Field 2009). In light of the above, it can be argued that given the small standard deviations relative to the mean, the data and the attendant results represent the true reality.

Furthermore, in order to establish the relationship between employee optimism, status competitiveness, interpersonal adaptability and employee altruism amongst Uganda hotels' staff, we first examined zero-order correlations coefficients (Table 5) between the variables. At this level of analysis, we established that the correlations between employee optimism and interpersonal adaptability are positively and significantly correlated $(\mathrm{r}=0.533, \mathrm{p}=0.01)$; the same is for employee optimism and status competitiveness ( $\mathrm{r}=0.472, \mathrm{p}=0.01)$; employee optimism and employee altruism $(\mathrm{r}=0.474, \mathrm{p}=0.01)$; interpersonal adaptability and status competitiveness were positive and significantly related $(\mathrm{r}=0.539, \mathrm{p}=0.01)$; interpersonal adaptability and employee altruism $(\mathrm{r}=0.605, \mathrm{p}=0.01)$; and status competitiveness and employee altruism $(\mathrm{r}=0.635, \mathrm{p}=0.01)$.

\section{Hypotheses Testing}

In order to test for the direct and indirect relationships as indicated in our hypothetical model, Smart-PLS 3.2 was applied (Henseler et al. 2015). In return, bootstrapping was equally applied so as to specify the standard errors and tstatistics. To determine the path's importance, the validity of the Partial Least square-structural equation model (PLS-SEM) was assessed based on the path 
coefficients and the significance of the path coefficients and the significance level. The resulting p-values were obtained using SmartPLS by using the bootstrapping process and calculating the p-value for each path. Path coefficients and significance levels were determined by randomly sampling 5,000 instances into the model. The results are presented in Table 6 which is supported by Figure 1.

Table 6. Means, Standard Deviations (SD) and Zero Order Correlations

\begin{tabular}{|l|c|c|c|c|c|c|}
\hline Study variables & Means & SD & $\mathbf{1}$ & $\mathbf{2}$ & $\mathbf{3}$ & $\mathbf{4}$ \\
\hline Employee Optimism (1) & 4.41 & 0.68 & 1 & & & \\
\hline Interpersonal adaptability (2) & 4.42 & 0.75 & $0.533^{* *}$ & 1 & & \\
\hline Status competitiveness (3) & 4.40 & 0.65 & $0.472^{* *}$ & $0.539^{* * *}$ & 1 & \\
\hline Employee Altruism (4) & 4.12 & 0.54 & $0.474^{* *}$ & $0.605^{* *}$ & $0.635^{* *}$ & 1 \\
\hline
\end{tabular}

**Correlation is significant at the 0.01 level (2-tailed); $n=303$.

Figure 1. PLS-SEM for Employee Altruism

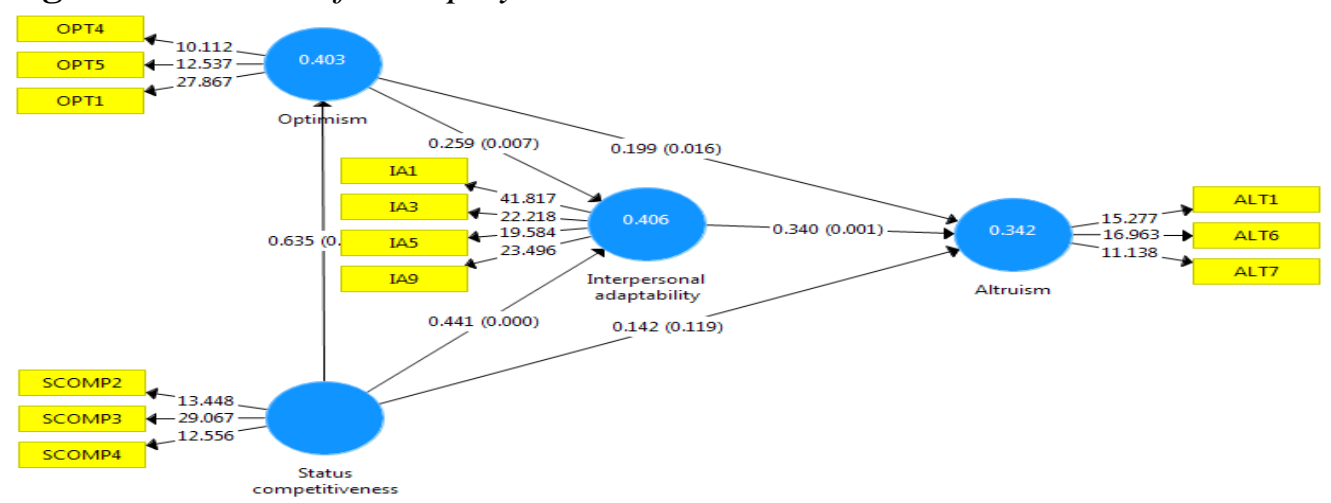

Figure 1 shows the results of the t-values of the outer model factor loadings and the inner model path coefficient and p-values. The size of the arrows represents the absolute value of each path. Table 6 summarizes the results of each proposed hypothesis.

The results show that there is a positive and significant relationship between interpersonal adaptability and employee altruism $(\beta=0.340, \mathrm{p}=0.001, \mathrm{t}$-values $=$ 3.445 with effect size of 0.104$)$. Also, a positive and significant relationship between optimism and altruism $(\beta=0.199, \mathrm{p}=0.016$, $\mathrm{t}$ - values $=2.417$ with effect size of $0.034)$, employee optimism and interpersonal adaptability $(\beta=0.259, \mathrm{p}=0.007$, $\mathrm{t}$ values $=2.690$ ). Additionally, we established that status competitiveness is positively and significantly associated with interpersonal adaptability and optimism $(\beta=0.441, p=0.000$, $t$-values $=5.072$, with effect size of $0.195 ; \beta=0.635$, $\mathrm{p}=0.000$, $\mathrm{t}$-value $=10.519$, with effect size of 0.676 ) but not significantly related with altruism $(\beta=0.142, p=0.119$, $t$-value $=1.562$, with effect size of 0.015$)$. Further, in terms of the predictive accuracy, coefficient of determination $\left(\mathrm{R}^{2}\right)$, the exogenous variables (interpersonal adaptability, status competitiveness and employee optimism,) explain $34.2 \%$ of the endogenous factor (employee altruism) which is considered a moderate effect and further supports our model's in-sample model fit (Hair et al. 2017). Hair et al. (2017) recommend that any predictive variance above zero (0) shows predictive relevance, as presented in Table 6. 


\section{Mediation Test Results}

To test for these indirect relationships, we followed Cepeda-Carrion et al.'s (2018) recommendations. Based on these guidelines, results presented in Tables 7 and 8 show that interpersonal adaptability has a positive and significant mediating effect in the relationship between status competitiveness, employee optimism and employee altruism $(\beta=0.150, p=0.006 ; \beta=0.088, p=0.042)$, with variance accounted for (VAF) of $31.65 \%$ and $30.66 \%$ in that order, confirming our theorized indirect relationship of status competitiveness, employee optimism and employee altruism through interpersonal adaptability. Additionally, employee optimism has a positive and significant mediating effect in the relationship between status competitiveness, altruism and interpersonal adaptability $(\beta=0.126, p=0.017 ; \beta=0.164, p=0.006)$ with VAF of $26.58 \%$ and $27.11 \%$ respectively. This confirmed our theorized indirect relationship of status competitiveness, altruism and interpersonal adaptability through optimism. This implies that optimism plays a complementary partial mediating role between status competitiveness, altruism and interpersonal adaptability.

Table 7. Results of the Direct Hypotheses Tested

\begin{tabular}{|l|c|c|c|c|c|}
\hline Direct Path & $\boldsymbol{\beta}$ & S. D & T Stat & P Values & f \\
\hline Interpersonal adaptability -> Altruism & 0.340 & 0.099 & 3.445 & 0.001 & 0.104 \\
\hline Optimism -> Altruism & 0.199 & 0.082 & 2.417 & 0.016 & 0.034 \\
\hline Optimism -> Interpersonal adaptability & 0.259 & 0.096 & 2.690 & 0.007 & 0.067 \\
\hline Status competitiveness -> Altruism & 0.142 & 0.091 & 1.562 & 0.119 & 0.015 \\
\hline Status competitiveness -> Interpersonal adaptability & 0.441 & 0.087 & 5.072 & 0.000 & 0.195 \\
\hline Status competitiveness -> Optimism & 0.635 & 0.060 & 10.519 & 0.000 & 0.676 \\
\hline
\end{tabular}

Table 8. Mediation Test Results

\begin{tabular}{|l|c|c|c|c|c|}
\hline Direct Path & $\boldsymbol{\beta}$ & S.D & T Stat & $\begin{array}{c}\text { P } \\
\text { Values }\end{array}$ & \\
\hline Interpersonal adaptability -> Altruism & 0.340 & 0.099 & 3.445 & 0.001 & \\
\hline Optimism -> Altruism & 0.199 & 0.082 & 2.417 & 0.016 & \\
\hline Optimism -> Interpersonal adaptability & 0.259 & 0.096 & 2.690 & 0.007 & \\
\hline Status competitiveness -> Altruism & 0.142 & 0.091 & 1.562 & 0.119 & \\
\hline Status competitiveness -> Interpersonal adaptability & 0.441 & 0.087 & 5.072 & 0.000 & \\
\hline Status competitiveness -> Optimism & 0.635 & 0.060 & 10.519 & 0.000 & \\
\hline Indirect Path & $\boldsymbol{\beta}$ & S. D & T Stat & P & VAF \% \\
\hline Optimism -> Interpersonal adaptability -> Altruism & 0.088 & 0.043 & 2.041 & 0.042 & $30.66 \%$ \\
\hline Status competitiveness -> Interpersonal adaptability -> Altruism & 0.150 & 0.054 & 2.757 & 0.006 & $31.65 \%$ \\
\hline Status competitiveness -> Optimism -> Altruism & 0.126 & 0.053 & 2.391 & 0.017 & $26.58 \%$ \\
\hline Status competitiveness -> Optimism -> Interpersonal adaptability & 0.164 & 0.060 & 2.742 & 0.006 & $27.11 \%$ \\
\hline Total Effects & $\boldsymbol{\beta}$ & S. D & T Stat & P & Values \\
\hline Interpersonal adaptability -> Altruism & 0.340 & 0.099 & 3.445 & 0.001 & \\
\hline Optimism -> Altruism & 0.287 & 0.091 & 3.169 & 0.002 & \\
\hline Optimism -> Interpersonal adaptability & 0.259 & 0.096 & 2.690 & 0.007 & \\
\hline Status competitiveness -> Altruism & 0.474 & 0.066 & 7.194 & 0.000 & \\
\hline Status competitiveness -> Interpersonal adaptability & 0.605 & 0.053 & 11.458 & 0.000 & \\
\hline Status competitiveness -> Optimism & 0.635 & 0.060 & 10.519 & 0.000 & \\
\hline
\end{tabular}




\section{Discussion}

The central objective of this investigation was to examine the predictive relationship between employee optimism, status competitiveness interpersonal adaptability and employee altruism under the current COVID-19 pandemic. Findings reveal that there is a positive and significant relationship between employee optimism, interpersonal adaptability and altruism; status competitiveness, interpersonal adaptability and employee altruism; status competitiveness, employee optimism and employee altruism; and status competitiveness, employee optimism and interpersonal adaptability. These results have the following implications in the context of Uganda hotels:

\section{Employee Optimism, Interpersonal Adaptability and Altruism}

Results indicate that there is a positive and significant relationship between employee optimism and employee altruism; employee optimism and interpersonal adaptability; interpersonal adaptability and employee altruism; employee optimism, interpersonal adaptability and employee altruism; and that interpersonal adaptability mediates in the relationship between employee optimism and employee altruism. This finding is supported by the works of Xiao et al. (2020) who argue that workplace friendship is the manifestation of interpersonal relationships in the workplace, which in turn, raise the emotions that workers have and the need to help each other. As applied to the context, these relationships imply the following.

Employees that have positive expectations in whatever they do with and for the organization, are bound to ensure that they go out of their way to foster the general welfare of those in need without expecting to be paid. In other words, Uganda hotels' staff who are optimistic that they will succeed, even when faced with major challenges as those conditioned by the COVID-19 pandemic, will always help others who have heavy workloads at their places of work regardless of the COVID-19 pandemic challenges. Further, it means that under uncertain times such as the COVID-19 pandemic, staff that usually expect the best from their hotels will always willingly give off their time to help others who have workrelated problems in their workplaces.

Staff that derive positive expectations in all that they do for their employer will always blend with others, regardless of the challenges they are undergoing under the COVID-19 pandemic. In other words, hotel staff in Uganda that find it easy to relax while at their workplaces will always try to understand the viewpoints of their counterparts so as to improve their interaction with them, regardless of the prevailing challenges conditioned by the COVID-19 pandemic. Further, it means that staff of Uganda hotels that are dedicated to doing well for their hotels regardless of the challenges that they undergo such as those associated with COVID-19 pandemic, are always willing to adapt their work practices to the requirements and suggestions of their colleagues. The purpose will always be to ensure that they keep doing well for their own benefit and the employer. 
Employees that have the ability to interact with one another freely can easily be able to offer help to one another regardless of the challenges they undergo during the COVID-19 pandemic. In other words, Uganda hotels' staff that do not consider negative comments about their work very important so as not to get derailed, are likely to offer orientation to new employees of the hotels, even though it is not required by the hotels that employ them, let alone the fact that they are undergoing stringent conditions under this COVID-19 pandemic. In addition, this means that Uganda hotels' staff that regard the act of developing good relationships with all their counterparts as an important factor for them to be effective regardless of the COVID-19 pandemic situation, will always offer help that is intended to make their colleagues become more productive. This finding is in part supported by the scholarly works of Yin et al. (2018), who argue that workplace friendship can positively affect employees' attitudes toward work and as such, their mates.

Employees who interact with one another freely, will always have positive expectations in whatever they do regardless of the COVID-19 pandemic situation, so as to be able to offer help to others in need. In other words, hotel staff that freely relate with one another, will always have positive expectations in whatever they do regardless of the COVID-19 pandemic situation. In turn, this will always make them ready to offer assistance to one another at all costs. In support of this relationship, Yin et al. (2018) have humbly argued that workplace friendship cannot be existent without such employee perceptions of optimism, interpersonal adaptability and selfless behaviors towards one another. Relatedly, it means that Uganda hotels' staff that try to understand the viewpoints of their counterparts so as to improve their interaction with them, are always optimistic that they will succeed, even when faced with major challenges such as those associated with the COVID-19 pandemic. In return, such staff can easily offer help to others so as to make them more productive.

These findings are supported by existing theories such as the interpersonal theory (Kiesler 1996). This theory is derived from the notion of interpersonal reciprocation. It maintains that people in a relationship choose to behave in such ways that maintain or reflect similar previous actions and expectations towards each other. This implies that the actions of one party in a relationship simply depict and reaffirm what the other did before. The result is a relationship characterized by give and return behaviors amongst the interactants. Under such a relationship, there is inherent constructive interactions (interpersonal adaptability), given the reciprocal interactions (optimism) since the positive actions of one party inevitably build similar positive expectations from another. Hence, the need to offer help to each other at all costs without expecting a reward becomes a norm (altruism). This is how interpersonal theory anchors the relationship between interpersonal adaptability, employee optimism and employee altruism. To date, there is a dearth of literature to attest to this relationship. 


\section{Status Competitiveness, Interpersonal Adaptability and Employee Altruism}

Results indicate that there is a positive and significant relationship between status competitiveness and employee altruism; status competitiveness and interpersonal adaptability; interpersonal adaptability and employee altruism; status competitiveness, interpersonal adaptability and employee altruism; and that interpersonal adaptability mediates in the relationship between status competitiveness and employee altruism. These findings could be supported by Anjum et al. (2019) who argue that when there is a high level of friendship amongst workers in an organization (interpersonal adaptability), employees respond by resurrecting their emotional needs (such as being optimistic), and will continue working in the organization in any capacity of choice (status competitiveness) and inevitably wanting to help each other at all costs (altruism).These findings further imply the following.

This implies that Uganda hotels' staff that are convinced that competition for any status in the structures of the hotels is guaranteed, will always be available to offer help intended to improve the welfare of others in their organization regardless of the COVID-19 pandemic situation. In addition, this means that staff that believe that their status at work depends on their performance in relation to others are likely to help others so as to make them become more productive regardless of the COVID-19 pandemic situation.

This means that Uganda hotels' staff that believes that promotions in their hotels are only given when one outperforms others, can easily try to understand the viewpoints of their counterparts so as to improve their interaction with them regardless of the COVID-19 pandemic situation. Further, it means that Uganda hotels' staff that believe that they can only be able to obtain high status if they outperform their coworkers, easily develop good relationships with most, if not all, of their counterparts as an important factor for their effectiveness regardless of the COVID-19 pandemic situation.

Uganda hotels' staff that do not consider negative comments about their work to be very important, will always believe that occupation of any status in their hotels depends on one's performance relative to others, regardless of the COVID-19 pandemic situation. In return, such staff is bound to offer help to others who have heavy workloads in their workplaces. In addition, Uganda hotels staff who believe that developing good relationships with most, if not all, of their counterparts is an important factor of their effectiveness, are likely to believe that only the best employees can obtain high status at work regardless of the COVID-19 pandemic situation and these can offer help to others make them more productive. This relationship is supported by Yu et al. (2021) who argue that workplace friendship results in the achievement of an individual's emotional needs in the organization, knowledge sharing, mutual help among workmates, harmonious working atmosphere characterized by mutual trust and love. This ultimately increases resource investment in extra-role behavior.

Theoretically, these findings are equally supported by the social comparison theory (Festinger 1954). This theory argues that there is always an element of competition in a social system for people to either raise or maintain particular 
social statuses in an organization. This means that once the spirit of competition is accepted as a norm in an organization, there is a possibility for members to relate easily with one another so that they can even go beyond the call of duty by way of being able to offer help to others so that their welfare can be improved. This is the extent to which status competiveness, interpersonal adaptability and employee altruism can be anchored by the social comparison theory (Festinger 1954). In the same breath, there is limited empirical evidence to support these findings.

\section{Status Competitiveness, Employee Optimism and Employee Altruism}

Results indicate that there is a positive and significant relationship between status competitiveness and employee altruism; status competitiveness and employee optimism; employee optimism and employee altruism; status competitiveness, employee optimism and employee altruism; and that employee optimism mediates in the relationship between status competitiveness and employee altruism. This finding is supported by Wei et al. (2019) who argue that a positive emotional state in employees has a direct effect on their work attitude and thoughts. In turn, this affects their extra role behaviors. These findings have the following implications:

Once Uganda hotels' staff comes to believe that formal titles such as director of human resource management, manager outside catering etc., are contingent on one's performance relative to others in their hotels, then, staff become optimistic that they will succeed even when faced with major challenges such as the ones associated with the COVID-19 pandemic. Further, as long a Uganda hotels' staff is convinced that ranks and privileges are based on outperforming others in their respective hotels, then they are likely to become dedicated to doing well their work.

This finding equally means that whenever Uganda hotels' staff is convinced that responsibilities in their hotels are delegated based on one's performance relative to others, then it is likely that their formal actions will be associated with a sense of profound purpose regardless of the COVID-19 pandemic situation. In return, such staff cannot avoid helping others who have been absent from their work stations for genuine reasons. In addition, as long as Uganda hotels' staff believe that everybody must compete for every prestigious position in their hotels regardless of the COVID-19 pandemic situation, they are likely to become dedicated to doing well in their work. In return, such staff is bound to willingly give off their time to help others who have work-related problems in their hotels.

Theoretically, these findings are equally supported by the social comparison theory (Festinger 1954). This is because, as argued before, this theory maintains that there is always an element of competition in a social system for people to either raise or maintain particular social statuses in an organization. This implies that with the acceptance of a spirit of competition in an organization, members can then have positive expectations in what they do for the organization. This in return, makes them offer help to each other given the justice associated with the spirit of competition in the organization. 


\section{Status Competitiveness, Employee Optimism and Interpersonal Adaptability}

Results equally indicate that there is a positive and significant relationship between status competitiveness and interpersonal adaptability; status competitiveness and employee optimism; employee optimism and interpersonal adaptability; status competitiveness, employee optimism and interpersonal adaptability; and that employee optimism mediates in the relationship between status competitiveness and interpersonal adaptability. Given that most of what this relationship implies has been discussed above, what remains is the inherent relationship between status competitiveness, employee optimism and interpersonal adaptability and the extent to which employee optimism mediates in this relationship.

Uganda hotels' staff convinced that ranks and privileges are based on outperforming others in their respective hotels regardless of the COVID-19 pandemic situation, are likely to become dedicated to doing well in their work and can adjust their work practices if someone points out a better solution. Uganda hotels' staff need to be optimistic that they will succeed, even when faced with major challenges such as those associated with the COVID-19 pandemic, for them to develop a feeling that they are able to obtain high status if they outperform their coworkers. In doing so, they are bound to adjust their work practices if someone points out a better solution to any challenge they face while working. This could be supported by Wei et al. (2019) who allude to the argument that employees that are optimistic, have improved work attitudes and thoughts. In return, this brings about employee altruism as a form of extra role behaviors.

Theoretically, these findings are as well-supported by the social comparison theory (Festinger 1954) and the interpersonal theory (Kiesler 1996). This is because the spirit of competition guarantees positive expectations among staff of an organization, and this in turn could make them interact meaningfully amongst each other as advanced by the interpersonal theory. However, in the same breath, there is limited empirical evidence to support these findings.

\section{Conclusions}

This paper presents an examination of the relationship between employee optimism, status competitiveness interpersonal adaptability and employee altruism. Based on the findings of the study, it can be concluded that staff that is optimistic that they will succeed, even when faced with major challenges such as those associated with the COVID-19 pandemic, can try to understand the viewpoints of their counterparts so as to improve their interaction with them. This tendency makes them ready to offer help to others so as to make them more productive.

In order for staff to believe that occupation of any status in their organization depends on one's performance relative to others, they need at times to disregard the majority of the negative comments made by others because they have a duty to offer help to others who have heavy workloads in their workplaces regardless of the COVID-19 pandemic situation. 
Staff needs to believe that each and everybody must compete for every prestigious position in their organization regardless of the COVID-19 pandemic situation, if they are likely to become dedicated to doing well their work and interact with one another more meaningfully in the pursuit of organizational goals and objectives.

Staff needs to positively expect to succeed even in face of competition for the different positions in the organization particularly if a culture of offering help to one another is to be nurtured in the organization regardless of the COVID-19 pandemic situation.

\section{Implications of the Study}

At a theoretical level, the interpersonal theory (Kiesler 1996), explains employee optimism, interpersonal adaptability and employee altruistic behaviors. In a constructive interpersonal relationship, there is inherent expectation for the best, based on previous experiences by the interactants, which the parties flexibly adjust to one another's ways of life and can be available to assist one another at all costs. However, the theory does not argue for interpersonal behaviors being competitive at all. This is because the actions of the interactants are voluntarily induced by the actions of the other (Kiesler 1996). Therefore, status competitiveness could be explained by the social comparison theory (Festinger 1954). This theory maintains that elements of competition exist in a social system so as to enable parties to rise or maintain a particular social status in an organization.

At policy level, regardless of the pandemic, the willingness and necessity to offer assistance to others in the same workplace should be explicit in the core values of the organization. This is why organizations need to be clear on how they foster positive expectations on the part of their employees, how they do not segregate any employee when it comes to competition for the positions in the structure when they fall vacant, and how they encourage positive interactions amongst their members. These ideals need to be documented and communicated explicitly so that they retain as much clarity necessary to induce their full implementation. This is because they have been found to impact essential employee altruistic behaviors.

Managerially, this is a direct invitation of supervisors in organizations to ensure that if employees are to sacrifice their resources for the sake of others' welfare, there is a need for them to always have positive expectations in the actions of the organization, and they should be certain that they are free to compete for the various positions in the structure, have to be able and willing to interact freely with one another in the organization. This is because all these standards have been found to have an effect on the level of sacrifice that an employee can make to the welfare of the organization. 


\section{Study Limitations and Future Research Directions}

In the explanation of employee altruistic behaviors, this study has specifically considered the role of employee optimism, interpersonal adaptability and status competitiveness. Future studies could explore the role of other factors in ensuring the growth and development of employee altruistic behaviors. Such factors as cultural adaptability, training and learning efforts, ability to deal with uncertain and unpredictable work situations, competitive recognition, co-worker competitiveness, and more, directly impact the willingness to sacrifice for others in the organization. However, these have not been considered in the recent scholarly efforts intended to explain employee altruistic behaviors.

\section{References}

Anjum MA, Liang D, Durrani DK, Ahmed A (2019) Workplace ostracism and discretionary work effort: a conditional process analysis. Journal of Management and Organization 23: 1-18.

Cameron KS, Bright D, Caza A (2004) Exploring the relationship between organizational virtuousness and performance. American Behavioral Scientist 47(6): 766-790

Carver CS, Scheier MF (2014) Dispositional optimism. Trends in Cognitive Sciences 18(6): 293-299.

Cepeda-Carrion G, Cegarra-Navarro J-G, Cillo V (2018) Tips to use partial least squares structural equation modelling (PLS-SEM) in knowledge management. Journal of Knowledge Management

Charbonnier-Voirin A, Roussel P (2012) Adaptive performance: a new scale to measure individual performance in organizations. Canadian Journal of Administrative Sciences/Revue Canadienne Des Sciences de l'Administration 29(3): 280-293.

Festinger L (1954). A theory of social comparison processes. Human Relations 7: 117140.

Field A. (2009) Discovering statistics using SPSS. $3^{\text {rd }}$ Edition. London: SAGE Publications.

Fletcher TD, Nusbaum DN (2010) Development of the competitive work environment scale: a multidimensional climate construct. Educational and Psychological Measurement 70(1): 105-124.

Gefen D, Straub DW (2005). A practical guide to factorial validity using PLS-graph: tutorial and annotated example. Communications of the AIS 16: 91-109.

Green WS (2005) Introduction: altruism and the study of the religion. Altruism in world religions. Georgetown University Press.

Hair JF, Hollingsworth CL, Randolph AB, Chong AYL (2017). An updated and expanded assessment of PLS-SEM in information systems research. Industrial Management \& Data Systems 117(3): 442-458.

Henseler J, Ringle CM, Sarstedt M (2015) A new criterion for assessing discriminant validity in variance-based structural equation modeling. J. of the Acad. Mark. Sci. 43: $115-135$.

Kiesler DJ (1996) Contemporary interpersonal theory and research: personality, psychopathology, and psychotherapy. New York: Wiley.

Organ DW (1988) Organizational citizenship behavior: the good soldier syndrome. Lexington, MA: DC Heath. 
Savulescu J, Wilkinson D (2020) Extreme altruism in a pandemic. Journal of Medical Ethics blog.

Washington M, Zajac EJ (2005) Status evolution and competition: theory and evidence. The Academy of Management Journal 48(2): 282-296.

Wei W, Huang CY, Zhang Q (2019). The influence of negative emotions on organizational citizen behavior and anti-production behavior, self-control perspective. Management Review 31(12): 21-35.

Xiao J, Mao JY, Quan J, Qing T (2020). Relationally charged: how and when workplace friendship facilitates employee interpersonal citizenship. Frontiers in Psychology 11: 190.

Yin K, Sun JM, Zhang KL, Chen LN (2018). The effect of workplace friendship on voice behavior: a moderated mediation model. Management Review 30(4): 132-141.

Yu S, Wu N, Liu S and Gong X (2021) Job insecurity and employees' extra-role behavior: moderated mediation model of negative emotion and workplace friendship. Frontiers in Psychology 12(Apr): 631062. 
